\title{
BUCCAL FAT PAD WITH SANDWICH GRAFT VERSUS BUCCAL FAT PAD WITH BLOCK GRAFT IN CLOSURE OF OROANTRAL COMMUNICATION: PROSPECTIVE CLINICAL STUDY
}

\author{
Mohammed Ali Hassan ${ }^{* 1}$, Mansour Mohammed Hussien², Abdel Aziz Baiomy Abdullah ${ }^{3}$
}

\begin{abstract}
Objective: The present study was performed to evaluate the efficacy of buccal fat pad with sandwich graft versus buccal fat pad with bone block graft in closure of oroantral communication. Subjects and Methods: Patients of the present study were selected from those attending the outpatient clinic of Oral and Maxillofacial Department at Faculty of Dental Medicine, Al Azhar University (Assiut Branch). Fourteen patients with oroantral communications were divided in two groups: (group I) treated with sandwich graft covered by buccal fat pad, and (group II) treated by bone block covered by buccal fat pad. Results: Closure of oroantral communication was successful in both groups. No patient had any infection, graft exposure and /or loss, soft tissue dehiscence. Radiographic analysis revealed significant increase in bone density fo both groups, (from $693.5 \pm 28.61$ immediately postoperative to $805.2 \pm 28.06$ after 9 months) for G (I) And (from $590.0 \pm 30.24$ immediately postoperative To $683.3 \pm 16.59$ after 9 months) for G (II). Also, there was significant decrease in bone height in bone height in both groups at 6 and 9 months. Conclusion: Closure of OAC with buccal fat pad and bone graft not only gives excellent soft tissue healing, but also compensate the underlying bone defect.
\end{abstract}

KEY WORDS: Oroantral communication; Buccal fat pad; Sandwich graft; Closure of OACs.

\section{INTRODUCTION}

An oroantral communication (OAC) is a pathologic connection between the oral cavity and the maxillary sinus ${ }^{(1)}$. In most cases OACs are the result of extraction of maxillary premolars and molar teeth due to the close relationship between their roots and the maxillary sinus floor ${ }^{(2)}$. Many techniques and treatment modalities have been described for the closure of OAC, such as buccal advancement flap, palatal flap, buccal pad fat grafts, and distant flaps ${ }^{(1-5)}$.

The buccal fat pad (BFP) is a lobulated mass of fatty tissue surrounded by a slight capsule, located inside the masticatory spaces ${ }^{(6,7)}$. The easy mobilization, its excellent blood supply, the proximity of the BFP for the recipient area, and minimal donorsite morbidity are clear advantages of the BFP as a graft material ${ }^{(8-10)}$. In recent years, BFP has been used successfully for closing oral defects due to its

1.Assistant lecturer, Department of Oral and Maxillofacial Surgery. Faculty of dental medicine, Al-Azhar University, (Assiut Branch).

2.Professor, Department of Oral and Maxillofacial Surgery. Faculty of Dental Medicine, (Boys - Cairo), Al-Azhar University.

3. Assistant Professor and Head of Department of Oral and Maxillofacial Surgery. Faculty of Dental Medicine, Al-Azhar University, (Assiut Branch).

-Corresponding author: mada_20200@yahoo.com 
reliability and easy harvesting. It can provide a $6 \times$ $5 \times 3 \mathrm{~cm}$ graft which can cover an area of $10 \mathrm{~cm}^{2}$. The mean thickness is about $6 \mathrm{~mm}$. Care should be taken while harvesting to avoid injury to the parotid duct and facial nerve branches ${ }^{(8,9)}$.

Although the high success rate of these methods, they were limited in soft tissue closure, and this is in opposite side for the rising demand for implant rehabilitation ${ }^{(11)}$. Therefore, numerous bone grafts have been proposed for closure of OAF such as autogenous bone grafts, allografts, xenografts, alloplastic materials ${ }^{(11-14)}$.

Autogenous bone graft is considered the gold standard in grafting procedures. It provides osteogenic, osteoconductive, and osteoinductive properties without any immune reaction ${ }^{(12)}$. However, autogenous bone grafting has some negative aspects include second surgical procedure for bone harvesting and donor site morbidity. Because of these factors other grafting materials have been investigated ${ }^{(14)}$.

Allografts occur between genetically non-identical members of the same species. They eliminate the morbidity associated with harvesting autografts and provide an unlimited quantity of graft material ${ }^{(15)}$. Allografts provide both osteoinduction and osteoconduction to the graft site. Unfortunately, the extensive processing required to diminish the immunogenic properties of bone allografts and to preserve them for storage makes them expensive, renders them mechanically weaker, and eliminates the osteogenic cells ${ }^{(12)}$.

Ogunsalu (16) achieved both bony (hard tissue) and soft tissue using porcine collagen membrane and non-sintered bovine bone materials to close OAFs. Radiographically, bony healing of the defect was observed after 8 months. The technique offers the unique advantage that no donor site surgery is necessary ${ }^{(17)}$. So, this study was performed to evaluate the effectiveness of sandwich graft with pedicled BFP versus bone block with pedicled BFP in closure of $\mathrm{OAC}$ and bone regeneration.

\section{SUBJECTS AND METHODS}

The study was carried on 14 patients aged 28-55year. They were selected from Oral and Maxillofacial Surgery Outpatient Clinic, Faculty of Dentistry, Al-Azhar University, Assiut branch. Informed consent was obtained from all patients before any study procedures were performed. The clinical study extended from 2018 till 2020 year. All the patients were free from any local or systemic condition that may interfere with healing process.

Patients were divided into two groups. Group I: Patients underwent surgical closure of OAC with sandwich and buccal fat pad graft while group II, Patients underwent surgical closure of OAC with block and buccal fat pad graft.

One day before surgery, all patients received amoxicillin/clavulanic acid (Augmentin; GlaxoSmithKline) and metronidazole (Flagyl; Sanofi Aventis), Ibuprofen (Brufen; Kahira Pharmaceuticals \& Chemical Industries company) nasal decongestant Xylometazoline hydrochloride (Otrivin 0.1\% Nasal Drops; Dawaya), and 2\% chlorhexidine mouth wash (Hexitol, Adco, Egypt).

After patient preparation and administration of local anesthesia, a circular incision with a 2-mm margin was made around the OAC. Two divergent cuts were made from each end of the circular incision extending into the vestibule. The trapezoidal buccal mucoperiosteal flap was reflected from the alveolar process and the lateral wall of the maxilla.

\section{Sandwich graft preparation:}

Bone granules (Bio-Oss $₫$; Geistlich Biomaterials, Wolhusen, Switzerland) was sandwiched between sheaths of approximately trimmed collagen membrane (Bio-Gide ${ }^{\circledR}$ Geistlich Biomaterials, Wolhusen, Switzerland) which were previously sutured together in three sides using 3-0 vicryl suture the fourth side will be adequately closed using the same suture after the bone granules has inserted, thus creating a closed sandwich. The prepared sand- 
wich was tucked into the defect in such a way that it forms a convexity toward the sinus and a concavity toward the alveolar bone Fig. 1(a).

\section{Bone block:}

(Bio-Oss $®$; Geistlich Biomaterials, Wolhusen, Switzerland) bone block was trimmed to a suitable size making the oral side wider than the sinus side to prevent dislodgement of the graft into the sinus cavity and press fitted into the defect Fig. 1(b).

Buccal pad of fat:

The buccal pad of fat was exposed through a $1-\mathrm{cm}$ long vertical incision in the reflected periosteum posterior to the zygomatic buttress. The buccal pad of fat was gently advanced on the graft and secured to the palatal mucosa without tension, with 4-0 vicryl sutures Fig.1(c). Finally, the mucoperiosteal flap will be replaced in its original position.

\section{Postoperative care:}

Routine standard post-operative instructions were given to all patients including; application of ice, soft diet, maintaining good oral hygiene and avoid tongue rolling over the suture and nose blowing or sneezing with a closed mouth for 2 weeks. Pre-operative medicines wer continued for one more week along with analgesics. Sutures were removed after 7 days.

\section{Patient assessment:}

Clinically: Assessment of patients was done at the end of 1, 3, 6 weeks and 3 months based on the following parameters: Pain using visual analog scale (VAS), swelling (edema) using a flexible tape, the $(\mathrm{AC}+\mathrm{AD}+\mathrm{BE})$ three planes were measured in millimeter. The sum of $\mathrm{AC}+\mathrm{AD}+\mathrm{BE}$ was considered as the postoperative cheek dimension value, infection present/absent and graft accepted/rejected.

Radiologically: Density and height of bone formation was assessed using cone beam computed tomography (PlanmecaPromax 3D ${ }^{\circledR}$ Planmeca Oy, Finland) at 3, 6 and 9 months.

The statistical analysis will be done using Statistical Package for Social Sciences (SPSS).

\section{RESULTS}

Table (1) summarizes comparison between the different time periods in each group according to visual analog scale. Both groups showed a statistically a significant decrease in mean Visual analog scale measurements at 3 and 6 weeks and 3 months $\left(\mathrm{p}<0.001^{*}\right)$.

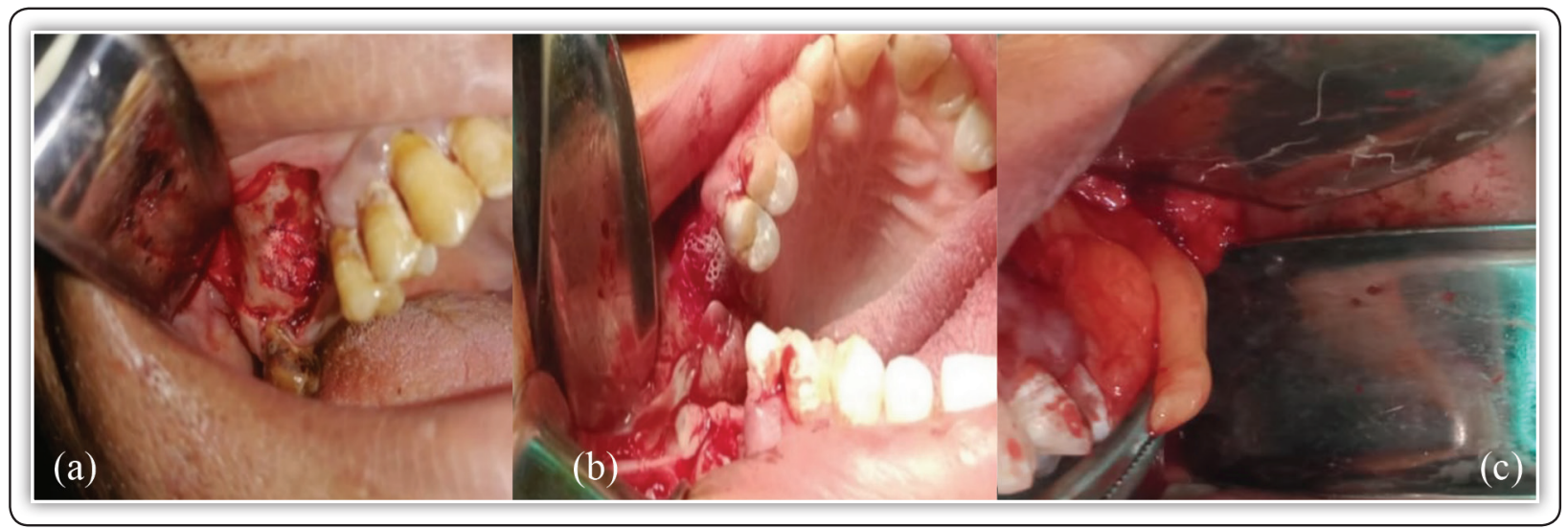

FIG (1) Clinical photos showing "a" sandwich graft filling the defect, "b" bone block of suitable size press fitted into the defect, "c" buccal pad of fat was gently advanced on the graft. 
TABLE (1): Comparison between the different time periods in each group according to visual analog scale

\begin{tabular}{|c|c|c|c|c|c|c|}
\hline & \multicolumn{4}{|c|}{ Visual analog scale (VAS) } & \multirow{2}{*}{$\mathbf{F r}$} & \multirow{2}{*}{$\mathbf{P}$} \\
\hline & After 1 week & After 3weeks & After 6weeks & After 3months & & \\
\hline Group I $(n=7)$ & $6.71 \pm 0.76$ & $2.86 \pm 0.69$ & $0.71 \pm 0.76$ & $0.14 \pm 0.38$ & \multirow{3}{*}{$19.985^{*}$} & \multirow{3}{*}{$<0.001^{*}$} \\
\hline $\mathbf{p}_{0}$ & & 0.121 & $0.001^{*}$ & $<0.001^{*}$ & & \\
\hline Sig. bet. Periods & & \multicolumn{3}{|c|}{$\mathrm{p}_{1}=0.098, \mathrm{p}_{2}=0.017^{*}, \mathrm{p}_{3}=0.469$} & & \\
\hline Group II $(n=7)$ & $7.14 \pm 0.69$ & $3.29 \pm 0.76$ & $1.0 \pm 0.82$ & $0.43 \pm 0.53$ & \multirow{3}{*}{$19.853^{*}$} & \multirow{3}{*}{$<0.001^{*}$} \\
\hline $\mathbf{p}_{0}$ & & 0.147 & $0.001^{*}$ & $<0.001^{*}$ & & \\
\hline Sig. bet. Periods & & \multicolumn{3}{|c|}{$\mathrm{p}_{1}=0.062, \mathrm{p}_{2}=0.013^{*}, \mathrm{p}_{3}=0.535$} & & \\
\hline
\end{tabular}

Fr: Friedman test, Sig. bet. Periods was done using Post Hoc Test (Dunn's)

$p: p$ value for comparing between the studied periods

$p_{0}: p$ value for comparing between After 1 week and each other period in each group

$p_{1}: p$ value for comparing between After 3 weeks and After 6 weeks in each group

$p_{2}: p$ value for comparing between After 3 weeks and After $\mathbf{3}$ months in each group

$p_{3}: p$ value for comparing between After 6 weeks and After 3 months in each group

*: Statistically significant at $p \leq 0.05$

Table (2) summarizes comparison between the different time periods in each group according to swelling (edema). Both group showed a statistically a significant decrease in mean swelling (edema) measurements at 3 and 6 weeks and 3 months $\left(\mathrm{p}<0.001^{*}\right)$.

TABLE (2): Comparison between the different time periods in each group according to swelling (edema)

\begin{tabular}{|c|c|c|c|c|c|c|c|}
\hline & \multicolumn{5}{|c|}{ Swelling (edema) (mm) } & \multirow{2}{*}{$\mathbf{F}$} & \multirow{2}{*}{$\mathbf{P}$} \\
\hline & Pre-operative & After 1 week & After 3 weeks & After 6weeks & After 3 month & & \\
\hline $\begin{array}{c}\text { Group } I(n= \\
7)\end{array}$ & $10.10 \pm 0.33$ & $11.14 \pm 0.40$ & $10.04 \pm 0.37$ & $9.83 \pm 0.33$ & $9.83 \pm 0.33$ & \multirow{2}{*}{$157.64^{*}$} & \multirow{2}{*}{$<0.001^{*}$} \\
\hline $\mathbf{p}_{0}$ & & $<0.001^{*}$ & 1.000 & $0.001^{*}$ & $0.001^{*}$ & & \\
\hline $\begin{array}{l}\text { Group II } \\
(n=7)\end{array}$ & $10.13 \pm 0.55$ & $11.09 \pm 0.49$ & $10.31 \pm 0.48$ & $9.83 \pm 0.52$ & $9.83 \pm 0.52$ & $198.91^{*}$ & $<0.001^{*}$ \\
\hline $\mathbf{p}_{0}$ & & $<0.001^{*}$ & 0.153 & $0.002^{*}$ & $0.002^{*}$ & & \\
\hline
\end{tabular}

F: F test (ANOVA) with repeated measures, Sig. bet. Periods was done using Post Hoc Test (adjusted Bonferroni) $p: p$ value for comparing between the studied periods

$p_{0}: p$ value for comparing between Pre-operative and each other period in each group

*: Statistically significant at $p \leq 0.05$

Table (3) summarizes comparison between the different time periods in each group according to bone density. Immediately post-operative, after 3, 6, and months, both groups showed a statistically a significant 
increase in mean bone density measurements at 3,6 and 9 months $\left(\mathrm{p}<0.001^{*}\right)$.

TABLE (3): Comparison between the different time periods in each group according to bone density

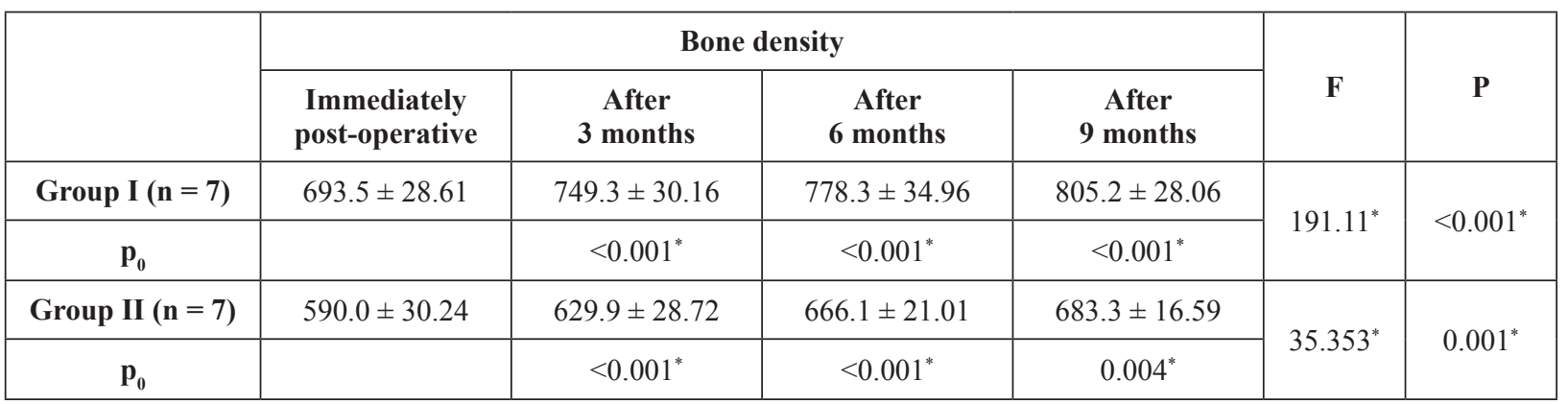

F: F test (ANOVA) with repeated measures, Sig. bet. Periods was done using Post Hoc Test (adjusted Bonferroni) $p: p$ value for comparing between the studied periods

$p_{0}: p$ value for comparing between immediately post-operative and each other period in each group

*: Statistically significant at $p \leq 0.05$

Table (4) summarizes comparison between the different time periods in each group according to bone height. Immediately post-operative, after 3,6 , and months, both groups showed a statistically a significant decrease in mean bone height measurements at 3,6 and 9 months $\left(\mathrm{p}<0.001^{*}\right)$.

TABLE (4): Comparison between the different time periods in each group according to bone height

\begin{tabular}{|c|c|c|c|c|c|c|}
\hline & \multicolumn{4}{|c|}{ Bone height } & \multirow[b]{2}{*}{$\mathbf{F}$} & \multirow[b]{2}{*}{$\mathbf{P}$} \\
\hline & $\begin{array}{c}\text { Immediately } \\
\text { post-operative }\end{array}$ & $\begin{array}{c}\text { After } \\
3 \text { months }\end{array}$ & $\begin{array}{l}\text { After } \\
6 \text { months }\end{array}$ & $\begin{array}{c}\text { After } \\
9 \text { months }\end{array}$ & & \\
\hline Group I $(n=7)$ & $9.18 \pm 0.27$ & $9.0 \pm 0.28$ & $8.75 \pm 0.29$ & $8.55 \pm 0.33$ & \multirow{2}{*}{$319.845^{*}$} & \multirow{2}{*}{$<0.001^{*}$} \\
\hline $\mathbf{p}_{0}$ & & $<0.001^{*}$ & $<0.001^{*}$ & $<0.001^{*}$ & & \\
\hline Group II $(n=7)$ & $8.97 \pm 0.33$ & $8.75 \pm 0.30$ & $8.31 \pm 0.40$ & $7.90 \pm 0.40$ & \multirow{2}{*}{$233.08^{*}$} & \multirow{2}{*}{$<0.001^{*}$} \\
\hline$p_{0}$ & & $0.001^{*}$ & $<0.001^{*}$ & $<0.001^{*}$ & & \\
\hline
\end{tabular}

F: F test (ANOVA) with repeated measures, Sig. bet. Periods was done using Post Hoc Test (adjusted Bonferroni) $p: p$ value for comparing between the studied periods

$p_{0}: p$ value for comparing between immediately post-operative and each other period in each group

*: Statistically significant at $p \leq 0.05$

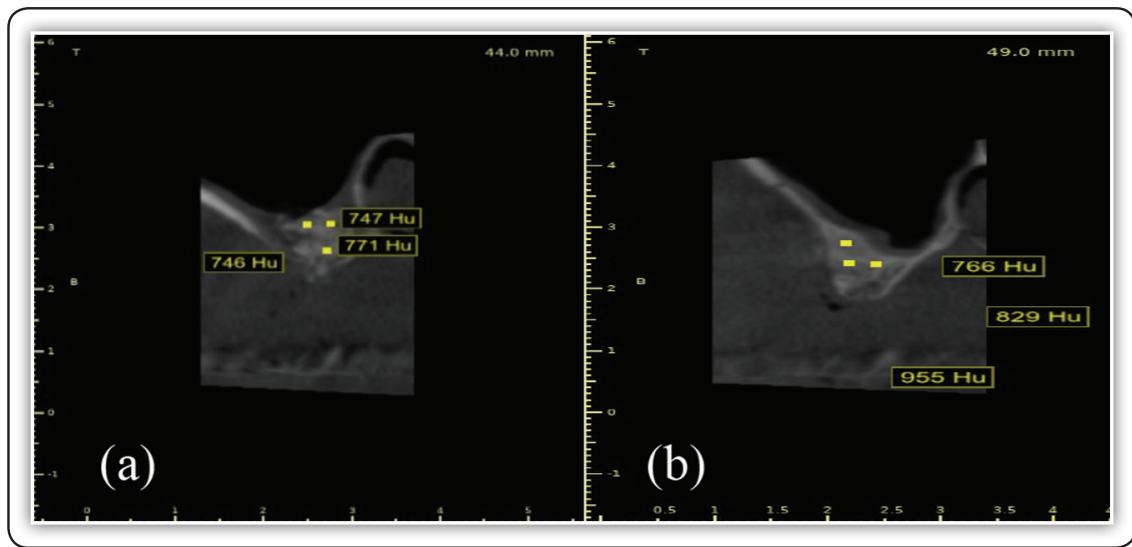

FIG (2) CBCT showing measurement of bone density (a) immediately postoperative. (b) After 9 months. 


\section{DISCUSSION}

The selection of treatment strategy of OAC is influenced by the amount and condition of tissue available for repair and the possible placement of dental implants in the future ${ }^{(13)}$. Many techniques have been proposed for the closure of OAC, including buccal or palatal flaps and their modifications. The preferred technique may vary from one clinician to another and case selection ${ }^{(18)}$.

The flap used in this study was buccal trapezoidal flap in agreement with Saleh and Issa ${ }^{(19)}$ whose considered that broad trapezoidal buccal flap had the privilege of providing adequate perfusion and enclosed direct access to the defect allowing for proper eradication of the infection and debridement of the necrotic tissues. The use of the buccal fat pad in the closure of OAF was first reported by Egyedi. ${ }^{(20)}$ The use of the BFP as a pedicle graft for closure of oral defects has been reported with good results. All cases treated in this study using the BFP were successful. Healing usually occurred within two to three weeks, leaving a good mucosal surface ${ }^{(21,22)}$. The experience in this study agrees with Rapidis et al. ${ }^{(22)}$, who believed that use of the BFP is easy, well tolerated and is an uncomplicated technique.

Saleh and Issa ${ }^{(19)}$ determined soft tissue grafting alone may not be appropriate to restore large and persistent fistulae, since the discontinuity of the bony floor of the maxillary sinus and violating the overlying sinus membrane is gravity sensitive. Bone grafting techniques have not only led to a proper anatomical closure, but also aided in the build-up of a more biological base, i.e., the reformation of lost bone structure.

Haas et al ${ }^{(11)}$ recently introduced an OAF closure technique that uses press-fitted monocortical block grafts that are harvested intraorally. The faults related to the collection of autogenous graft include: creation of another operating field, bone weakening in the donor site, extension of the treatment duration $^{(1,11)}$.
The bone substitute that was used for our study is the an-organic bovine bone. Various authors have reported the material to be suitable for sinus augmentation. The most commonly used product that has been reported in literature comes under the proprietary name of Bio-Oss ${ }^{\circledR}$ (Geistlich Pharma Switzerland) which is considered to be a highly biocompatible and osteoconductive material which leads to appropriate osseointegration of dental implants ${ }^{(23)}$.

The present study compared between two techniques for closure of the OAF, in which both hard (bone) and soft tissue closure was achieved for prosthetic rehabilitation purpose. This combination technique provides more stability and provides additional tissue for cover.

The present study used CBCT to follow the qualitative (bone density) and quantitive (bone height) changes in the augmented defect in agreement with the studies concluded that CBCT is a reliable technique with less effort, both for the investigator and for the patient, as it is noninvasive and technically supported for assessment of the graft after augmentation ${ }^{(24,25)}$.

Significant radiographic evidence of bone formation appeared in both group after 3 months postoperatively. Our results showed that Bio-Oss ${ }^{\circledR}$ exhibited good osteoconductive potential, this is in agreement with animal studies and clinical trials published by Zitzmann et al. ${ }^{(26)}$, Slotte et al. ${ }^{(27)}$, who reported that Bio-Oss ${ }^{\circledR}$ is a biocompatible substance that does not cause inflammation, allergies or any toxic reactions and coincide with the findings demonstrated by Ogunsalu ${ }^{(16)}$.

\section{CONCLUSION}

Results of the present study proved that combined use of sandwich technique or block graft together with BFP was a very simple, easy and helpful technique in closure of large OAFs. The use of BFP over the graft has the added advantage for graft 
support and minimizing the chance of graft resorption or wound dehiscence. The technique not only improved the bone healing but it also increased the success rate of closure of the OACs.

\section{REFERENCES}

1. Khandelwal P, Hajira N. Management of oro-antral communication and fistula: various surgical options. World J Plast Surg. 2017;6(1):3-8.

2. Visscher SH, van Minnen B, Bos RR. Closure of oroantral communications: a review of the literature. J Oral Maxillofac Surg. 2010; 68:1384-91.

3. von Wowern N. Closure of oroantral fistula with buccal flap: Rehrmann versus Moczar. Int J Oral Surg 1982 06;11(3):156-165.

4. Ehrl PA. Oroantral communication. Epicritical study of 175 patients, with special concern to secondary operative closure. Int J Oral Surg 1980 10;9(5):351-358.

5. el Hakim IE, el Fakharany AM. The use of the pedicled buccal fat pad (BFP) and palatal rotating flaps in closure of oroantral communication and palatal defects. J Laryngol Otol 1999 09;113(9):834-838.

6. Kim MK, Han W, Kim SG. The use of the buccal fat pad flap for oral reconstruction. Maxillofac Plast Reconstr Surg. Feb 25; 2017;39(1):5 .

7. Scott P, Fabbroni G, Mitchell D. The buccal fat pad in the closure of oro-antral communications: An illustrated guide. Dent Update. 2004;31(6):363-4, 366.

8. Allais M, Maurette PE, Cortez AL, Laureano Filho JR, Mazzonetto R. The buccal fat pad graft in the closure of oroantral communications. Braz J Otorhinolaryngol. 2008;74(5): 799 .

9. Singh J, Prasad K, Lalitha RM, Ranganath K. Buccal pad of fat and its applications in oral and maxillofacial surgery: A review of published literature (February) 2004 to (July) 2009. Oral Surg Oral Med Oral Pathol Oral Radiol Endod. 2010; 110 (6): 698-705.

10. Poeschl PW, Baumann A, Russmueller G, Poeschl E, Klug C, Ewers R. Closure of oroantral communications with Bichat's buccal fat pad. J Oral Maxillofac Surg. 2009;67(7):1460-6.

11. Haas R, Watzak G, Baron M, Tepper G, Mailath G, Watzek G. A preliminary study of monocortical bone grafts for oroantral fistula closure. Oral Surg Oral Med Oral Pathol Oral Radiol Endod. 2003; 96:263-6.
12. Penarrocha-Diago M, Garcia B, Gomez D, Balaguer J. Zygomatic bone graft for oral-antral communication closure and implant placement. J Oral Implantol 2007;33(5): 305-309.

13. Watzak G, Tepper G, Zechner W, Monov G, Busenlechner D, Watzek G. Bony press-fit closure of oro-antral fistulas: a technique for pre-sinus lift repair and secondary closure. J Oral Maxillofac Surg 2005 09;63(0278-2391; 9):12881294.

14. Zide MF, Karas ND. Hydroxylapatite block closure of oroantral fistulas: report of cases. J Oral Maxillofac Surg 1992 01;50(1):71-75.

15. Kapustecki M, Niedzielska I, Borgiel-Marek $\mathrm{H}$, Różanowski B. Alternative method to treat oroantral communication and fistula with autogenous bone graft and platelet rich fibrin. Med Oral Patol Oral Cir Bucal. 2016; 21:608-13.

16. Ogunsalu C. A new surgical management for oroantral communication:The resorbable guided tissue regeneration membrane--bone substitute sandwich technique. West Indian Med J 54:261-3, 2005.

17. Hariram, Pal US, Mohammad S, Singh RK, Singh G, Malkunje LR (2010) Buccal fat pad versus sandwich graft for treatment of oroantral defects: a comparison. Natl J Maxillofac Surg 1(1):6-14.

18. Parvini P, Obreja K, Sader R, Becker J, Schwarz F, Salti L. Surgical options in oroantral fistula management: a narrative review. Int J Implant Dent. 2018 Dec 27;4(1):40.

19. Saleh EA, Issa IA: Closure of large oroantral fistulas using septal cartilage. Otolaryngol Head Neck Surg. 2013 Jun; 148(6):1048-50.

20. Egyedi P. Utilization of the buccal fat pad for closure of oroantral and/or oro-nasal communications. J Maxillofac Surg 1977; 5:241.

21. Neder A. Use of buccal fat pad for grafts. Oral Surg Oral Med Oral Pathol. 1983;55(4): 349-50.

22. Tideman H, Bonsaquet A, Scott J. Use of the buccal fat pad as a pedicle graft. J Oral Maxillofac Surg 1986: 44: 435-440.

23. Piattelli M, Favero GA, Scarano A, Orsini G, Piattelli A. Bone reactions to anorganic bovine bone (Bio-Oss) used in sinus augmentation procedures: a histologic long-term report of 20 cases in humans. The International Journal of Oral \& Maxillofacial Implants. 1999;14(6):835-40. Epub 1999/12/29. 
24. Dellavia C, Speroni S, Pellegrini G, Gatto A, Maiorana C. A new method to evaluate volumetric changes in sinus augmentation procedure. Clin Implant Dent Relat Res 2014; 16:684-90.

25. Mazzocco F, Lops D, Gobbato L, Lolato A, Romeo E, del Fabbro M. Three-dimensional volume change of grafted bone in the maxillary sinus. Int J Oral Maxillofac Implants 2014; 29:178-84.
26. Zitzmann NU, Schärer P, Marinello CP, Schüpbach $P$, Berglundh T. Alveolar ridge augmentation with Bio-Oss: a histologic study in humans. Int J Periodontics Restorative Dent. 2001 Jun;21(3):288-95.

27. Slotte C, Lundgren D, Burgos PM. Placement of autogeneic bone chips or bovine bone mineral in guided bone augmentation: a rabbit skull study. Int J Oral Maxillofac Implants. 2003 Nov-Dec;18(6):795-806. 